\title{
ANÁLISE MICROBIOLÓGICA DE FORMIGAS CAPTURADAS EM AMBIENTE HOSPITALAR DA CIDADE DE ALFENAS/MG
}

\author{
Juliana da Silva MENEZES ${ }^{1}$ \\ Larissa Spuri LIMA ${ }^{2}$ \\ Bianca de Souza MOREIRA ${ }^{3}$ \\ Carlos Frederico LOIOLA ${ }^{4}$ \\ Jorge Kleber CHAVASCO ${ }^{5}$
}

1. Licenciatura em Ciências Biológicas pela Universidade Federal de Alfenas, UNIFAL-MG.

Email:julianatutora23@yahoo.com.br

2. Licenciatura em Ciências Biológicas pela Universidade Federal de Alfenas, UNIFAL-MG.

3. Farmacêutica pela Universidade José do Rosário Vellano, Unifenas.

4. Professor Titular de Parasitologia da Universidade José do Rosário Vellano - Unifenas.

5. Professor Associado de Microbiologia da Universidade Federal de Alfenas, UNIFAL-MG.

Recebido em: 04/02/2015 - Aprovado em: 15/06/2015 - Disponibilizado em: 15/07/2015

\section{RESUMO}

Um dos problemas associados à urbanização é o aumento no número de doenças causadas ou transmitidas pelos artrópodes. Esses animais constituem um perigo potencial à saúde pública, quando a infestação se dá em hospitais, por apresentarem a capacidade de transportar microrganismos patogênicos, atuando como vetores mecânicos. O objetivo foi verificar a contaminação de formigas encontradas em um hospital da cidade de Alfenas/MG. Os espécimes de formigas foram coletados de forma manual, com auxílio de pinças esterilizadas e, imediatamente, colocados em tubos de ensaio contendo $5 \mathrm{ml}$ de soro fisiológico estéril. As amostras, em soro fisiológico, foram inoculadas em Caldo BHI. Em seguida, os exemplares foram acondicionados em tubos de ensaio contendo álcool absoluto, para preservação e posterior identificação. A presença de microrganismos no tegumento das formigas foi identificada com a turvação do Caldo BHI - incubado a $37^{\circ} \mathrm{C}$ por 48 horas. Após cultivo, o material foi submetido às técnicas de isolamento e identificação dos microrganismos. Os principais gêneros de formigas encontrados foram Monomorium e Paratrechina. Os principais microrganismos identificados foram Staphylococcus aureus, Enterobacter aerogenes, Klebisiella pneumonie, Pseudomonas aeruginosa e Escherichia coli. A presença de bactérias potencialmente patogênicas no tegumento das formigas encontradas no ambiente hospitalar alerta para o fato de esses insetos serem potenciais vetores de doenças.

Palavras chave: Bactérias. Formigas. Hospital. Infecção microbiana. Vetores.

\begin{abstract}
One of the problems associated with urbanization is the increase in diseases caused or transmitted by arthropods. These animals constitute a potential danger to public health when the infestation occurs in hospitals, because they have the ability to carry pathogens, acting as mechanical vectors. The objective was verify the contamination of ants found in a city hospital Alfenas, MG. The specimens of ants were collected manually with the aid of sterile forceps and immediately placed in test tubes containing $5 \mathrm{~mL}$ of sterile saline. The samples in saline were inoculated in BHI broth. Then the specimens were placed in test tubes containing absolute alcohol for preservation and identification. Microorganisms in the integument of ants has been identified with the turbidity of the BHI broth - incubated at $37^{\circ} \mathrm{C}$ for 48 hours. After cultivation, the material was submitted to the techniques of isolation and identification of microorganisms. The main genera of ants were found Monomorium and Paratrechina. The main identified microorganisms, Staphylococcus aureus, Enterobacter aerogenes, Klebsiella pneumonie, Pseudomonas aeruginosa and Escherichia coli. The presence of potentially pathogenic bacteria in the integument of ants found in the hospital alert to the fact that these insects are potential vectors of diseases.
\end{abstract}

Keywords: Ants. Bacteria. Hospital. Microbial infection. Vectors. 


\section{Introdução}

A ocorrência de formigas em ambientes urbanos há muito vem sendo constatada e, à medida que a urbanização se intensifica, condições adequadas à sobrevivência desses insetos aumentam (CARNEIRO et al., 2008).

Nos últimos anos, a atenção está se voltando para as formigas que vivem em íntima associação com o homem em todo o mundo. O principal dano que podem acarretar é quando vivem em hospitais como vetores de patógenos (PELLI et al., 2006).

As formigas são insetos sociais, que vivem em colônias e são dominantes na maioria dos ecossistemas terrestres. Pertencentes aos Hymenoptera, esses insetos estão agrupados em uma única família, Formicidae. Mesmo assim, as diferenças de biologia e comportamento entre as várias espécies são acentuadas, variando desde a formiga doméstica, comum no interior de residências, infestando áreas alimentares; em hospitais, contaminando materiais, como soro fisiológico e outros equipamentos; e as formigas rurais, especializadas em cortar folhas e outras partes vegetais (ZARA, CAETANO e JAFFÉ, 2002).

Estima-se que existam mais de oito mil espécies de formigas em todo o mundo. São registradas três mil para a região neotropical e, destas, duas mil ocorrem no Brasil. Apesar da grande diversidade, apenas $1 \%$ das espécies de formigas é considerado praga e menos de 50 espécies estão adaptadas ao ambiente urbano. Embora as espécies de formigas consideradas como pragas sejam poucas, os danos causados por elas podem ser grandes. Além dos prejuízos econômicos, elas podem ser uma ameaça à saúde pública, atuando como vetores mecânicos de microrganismos patogênicos (WETLER et al., 2004).

O estudo de formigas em hospitais tem despertado grande interesse desde os primeiros relatos realizados por Beatson (1972) citado por Socolowsky e Cintra (2007), devido ao potencial de transmissão de infecções intra-hospitalares. Tais estudos têm demonstrado que um grande número de espécies de formigas é encontrado em hospitais de vários países, como Inglaterra, Chile e Alemanha (SOCOLOWSKY e CINTRA, 2007).

As formigas possuem capacidade de se deslocar com rapidez e normalmente percorrem extensas áreas, o que sugere que, além de se constituírem vetores de microorganismos em ambientes hospitalares, podem agir, também, como importantes vias de dispersão de microrganismos resistentes a drogas nesses ambientes (PEREIRA e UENO, 2008).

Estudos notórios da década de 70 constataram a presença dos gêneros de bactérias Salmonella, Staphylococcus, Klebisiella e Enterobacter em ambientes hospitalares, além de outros organismos 
patogênicos de importância (SCHULLER, 2004).

Existem alguns fatores que influenciam a presença de formigas em hospitais, como a estrutura arquitetônica, sua proximidade a residências, circulação de grande número de pessoas e roupas que podem conter ninhos, além dos alimentos, que são atrativos extras (BUENO e CAMPOSFARINHA, 1998).

Devido à sua facilidade de locomoção, as formigas podem transitar entre leitos, salas cirúrgicas, UTIs, enfermarias, cozinha e outras áreas dentro do recinto hospitalar e, na maioria das vezes, não são percebidas. Mesmo em hospitais que respeitam as medidas de controle de vetores recomendadas pelo Ministério da Saúde, é possível encontrar relatos destes himenópteros em seus diferentes compartimentos (FREITAS e TEIXEIRA, 2007).

As formigas podem estar associadas a vários tipos de incômodos, como irritações e lesões na pele e até mesmo necessidade de internação, podendo, ainda, em hospitais, falsear resultados laboratoriais por passarem de uma placa de Petri a outra, contaminando meios de cultura (FONTANA et al., 2009).

A diversidade de espécies de formigas encontradas em hospitais brasileiros tem se mantida elevada quando comparada com a mirmecofauna nos mesmos ambientes, em países de clima temperado, como Estados
Unidos, e países da Europa (BUENO e CAMPOS-FARINHA, 1998).

Considerando-se a importância do tema para a saúde pública, o objetivo deste trabalho é identificar micro-organismos patogênicos associados às formigas encontradas em um hospital da cidade de Alfenas/MG.

\section{Metodologia}

A pesquisa foi realizada no período de agosto de 2008 a julho de 2009 em um hospital privado da cidade de Alfenas/MG que atende a planos de saúde particulares e ao SUS.

Foram coletadas formigas no período vespertino, amostradas em vários pontos do hospital: cantinas, refeitórios, posto médico, sala de emergência, banco de sangue, corredores internos e externos, necrotério, local de carga e descarga de materiais e departamentos de atendimento e internação específicos, como pediatria, ginecologia, sala de exames e fonoaudiologia.

Os espécimes foram coletados manualmente, em torno de dez exemplares por área, retirados do local com pinças de pontas finas esterilizadas e, imediatamente, colocados em tubos de ensaio contendo $5 \mathrm{ml}$ de soro fisiológico estéril. Após agitação, 0,5ml das amostras, em soro fisiológico, foram inoculadas em $10 \mathrm{ml}$ de Caldo BHI (Brain Heart Infusion). Em seguida à inoculação em Caldo BHI, os exemplares 
foram acondicionados em tubos de ensaio contendo álcool absoluto, para preservação e posterior identificação por meio de lupas e imagens ampliadas, segundo Freitas e Teixeira (2007).

A presença de microrganismos no tegumento das formigas foi verificada pela turvação do Caldo $\mathrm{BHI}$, incubado a $37^{\circ} \mathrm{C}$ por 48 horas. As amostras positivas foram repicadas para os seguintes meios de cultura: Agar Sabouraud com antibiótico para isolamento de leveduras; Mannitol Salt Agar para isolamento de Staphylococcus sp; Agar BEM (Eosin Methylene Blue) para isolamento de bastonetes gram-negativos e Agar Cetrimid para isolamento de Pseudomonas aeruginosa. Após cultivo por 48 horas, a $37^{\circ} \mathrm{C}$, as placas foram analisadas para verificação de crescimento, e as colônias, posteriormente, identificadas por provas bioquímicas.

A identificação das formigas foi realizada por métodos comparativos, em que foram observadas as estruturas externas como: aparelho bucal, antenas, asa e abdome. Para o processo de identificação, foram utilizados os seguintes materiais: lupa óptica, placa de Petri, pincel e imagens ampliadas de formigas para comparação segundo Freitas e Teixeira (2007).

A análise estatística para comparar as proporções foi feita usando o qui quadrado por meio do software EpiInfo versão 6.04 do CDC. Foram consideradas significativas as diferenças, cujo $p$ value teve um valor menor ou igual a 0,05 .

\section{Resultados}

Devido ao método utilizado para identificação das formigas, não foi possível chegar até o nível de espécie; portanto, foram identificados os seguintes gêneros: Monomorium, Paratrechina, Pheidole $e$ Crematogaster. Houve diferença estatística entre os gêneros encontrados, e o gênero Paratrechina foi o mais prevalente, seguido pelo Monomorium $(p \leq 0,05)$. As espécies de micro-organismos encontradas foram Staphylococcus aureus, Staphylococcus epidermidis, Enterobacter aerogenes, Klebsiella pneumonie, Citrobacter freundii, P. aeruginosa e Escherichia coli. Devido ao fato de as amostras serem inoculadas em meios enriquecidos não foi feita a contagem de colônias dos exemplares. Não houve diferença estatística entre as espécies encontradas, pois todas as comparações de proporções tiveram um $p$ value $\geq 0,05$. Não foram detectadas leveduras pela técnica empregada. As formigas capturadas no refeitório, área externa do Centro de Estudo e Pesquisa (CEP), carga e descarga de materiais, alojamento e corredor do refeitório não apresentaram microrganismos que crescessem nos meios de cultura utilizados. 


\section{Discussão}

Foram encontrados quatro gêneros de formigas (Monomorium, Paratrechina, Pheidole e Crematogaster). Muitas das espécies coletadas apresentaram-se em áreas de risco, como locais de isolamento e internação.

Diferentemente das pesquisas realizadas por Santos, Fonseca e Sanches (2009) e Bueno e Campos-Farinha (1998), em que o gênero Pheidole apresentou maior ocorrência, neste estudo, o gênero Paratrechina foi o mais frequente, com $61 \%$ da abundância total.

Das 23 amostras coletadas, 18 (78\%) apresentaram crescimento. Esse resultado mostra a possibilidade de veiculação mecânica de microrganismos por formigas, igualmente aos estudos anteriores descritos por Zarzuela, Ribeiro e Campos-Farinha (2002) e Bueno e Campos-Farinha (1998).

Estudos bacteriológicos com a mirmecofauna hospitalar indicam a capacidade de algumas espécies atuar como vetores mecânicos de patógenos, o que é potencializado pelas características das formigas que facilitam sua infestação e dispersão em hospitais, como pequeno tamanho, grande mobilidade e alta capacidade reprodutiva. Esse é o caso do gênero com maior índice de prevalência neste estudo, Paratrechina, pequenas e com grande abundância de pilosidades na superfície externa de sua estrutura corpórea. $\mathrm{O}$ gênero
Paratrechina foi encontrado em áreas críticas, como posto médico, sala de emergência e banco de sangue, associado aos microrganismos S. aureus, S. epidermidis, E. aerogenes, $K$. pneumonie, $P$. aeruginosa e E. coli (BUENO e CAMPOS-FARINHA, 1998).

$\mathrm{O}$ gênero Monomorium, evidenciado em 30,44\% das coletas, também representa altos riscos à saúde pública quando ocorre em hospitais. Sua presença foi detectada, principalmente, na ala de pediatria e no necrotério, associada aos microrganismos $S$. epidermidis e $P$. aeruginosa (ZARZUELA, RIBEIRO e CAMPOS-FARINHA, 2002).

Os gêneros Crematogaster, assim como o Pheidole, tiveram ocorrência em apenas uma das áreas em que foram realizadas as coletas; o primeiro, capturado na ala de ginecologia (associado ao patógeno $P$. aeruginosa); e o segundo, na área destinada aos convênios e transplantes (associado ao patógeno K. pneumonie).

No ambiente externo ao hospital, também foi detectada a presença de bactérias patogênicas associadas às formigas, gênero Monomorium (S. aureus, S. epidermidis, E. aerogenes, $C$. freundii) e gênero Paratrechina (E. aerogenes e $S$. epidermidis).

Entre as sete espécies de bactérias isoladas, os principais grupos de patógenos foram os cocos gram-positivos e os bacilos gram-negativos. Destes, alguns, como $S$. aureus e $P$. aeruginosa, são comumente associados a infecções hospitalares. 
A veiculação de Staphylococcus sp por formigas, em ambientes hospitalares, evidencia elevado risco, especialmente pelo fato de esse micro-organismo ser o patógeno mais comumente causador de infecções hospitalares (SANTOS, FONSECA e SANCHES, 2009). Foi isolado em áreas críticas, como banco de sangue, sala de emergência e necrotério. Das formigas que foram identificadas como vetores de $S$. aureus e S. epidermidis, observou-se que, em alguns casos, os gêneros Paratrechina e Monomorium também veiculavam $E$. aerogenes, E. coli, $P$. aeruginosa e K. pneumonie.

P. aeruginosa foi isolada em ambientes como ala de pediatria e sala de emergência. De acordo com Ritchmann (2005), esse patógeno tem sido responsável pela maioria das pneumonias hospitalares. Já os casos de infecção hospitalar e bacteremia estão associados ao cateterismo e intubações. Devido à sua capacidade de adesão e à de formar filmes biológicos (biofilme), pode aderir a diferentes substratos utilizados na fabricação de sondas e cateteres (MENEZES et al., 2005). Ainda tem sido registrado como o segundo agente mais presente nas infecções hospitalares em pacientes queimados (RITCHMANN, 2005).

E. coli foi isolada em locais como ala de fonoaudiologia e sala de emergência. Mesmo fazendo parte do trato gastrointestinal dos seres humanos, tem sido reportada como um dos agentes mais importantes das infecções extraintestinais como trato urinário (SANTOS, FONSECA e SANCHES, 2009).

K. pneumonie, isolada em áreas como ala de ginecologia e banco de sangue, pode causar pneumonia, embora seja mais comum sua implicação em infecções hospitalares (aparelho urinário e feridas), particularmente em pacientes imunodeprimidos (SANTOS, FONSECA e SANCHES, 2009). Produz uma enzima chamada carbapenemase, por exemplo KPC, que confere resistência aos antimicrobianos carbapenêmicos, além de inativar penicilinas, cefalosporinas e monobactâmicos (DIENSTMANN et al., 2010).

Os micro-organismos mais frequentemente responsáveis por infecções hospitalares do trato urinário são: $E$. coli, $P$. aeruginosa e $K$. pneumoniae. Algumas bactérias multirresistentes, como Enterobacter $s p$, estão crescendo em incidência nesse quadro (MENEZES et al., 2005). A bactéria E. aerogenes, isolada de formigas capturadas em local crítico, como o posto médico, é causadora de infecções hospitalares, especialmente em unidades de terapia intensiva (SANTOS, FONSECA e SANCHES, 2009).

Estudos realizados por Wetler et al. (2004), em um hospital público de Ilhéus/BA, revelaram, também, os gêneros de formigas Paratrechina e Pheidole, contaminadas por bactérias consideradas potencialmente 
patogênicas, tais como: Pseudomonas sp, $S$. aureus, E. coli e K. pneumoniae.

No estudo desenvolvido por Tanaka, Viggiani e Person (2007), encontrou-se, comumente, o gênero de formiga Paratrechina, todas colonizadas por espécies bacterianas. Em todas as amostras, foram isolados bacilos gram-positivos. Os bacilos gram-negativos identificados foram $K$. pneumoniae e E. coli.

Pereira e Ueno (2008) indicaram alta frequência das bacterias Klebsiella $s p$ e Enterobacter sp, semelhante aos dados encontrados nesta pesquisa.

Em outro levantamento, Pelli et al. (2006) isolaram espécies bacterianas em formigas de ambiente hospitalar, destacandose Staphylococcus sp, bacilos gram-positivos e Pseudomonas sp. Os autores destacaram a necessidade de conhecer não apenas a existência de microrganismos carreados por insetos, mas a importância das espécies bacterianas, que podem se relacionar com doenças graves.

Segundo Bueno e Campos-Farinha (1998), há uma diversidade impressionante de formigas nos hospitais brasileiros; algumas dessas espécies são extremamente abundantes nesse tipo de ambiente; algumas espécies teriam certa "afinidade" por instrumentos cirúrgicos e materiais estéreis e são vetores potenciais de uma grande quantidade de micro-organismos oportunistas e/ou patogênicos ao ser humano, assim como visto neste trabalho. Não encontramos em outros trabalhos, dados semelhantes. A ausência de crescimento microbiano, na amostra capturada, poderia ser explicada pelo número reduzido de microrganismo ou pela presença de micro-organismos fastidiosos.

A erradicação de formigas em prédios urbanos é complexa, especialmente quando considerado o ambiente hospitalar. $\mathrm{O}$ uso de métodos convencionais, como a aplicação de inseticidas aerossóis e pós-químicos, pode causar danos indesejáveis ao ambiente e às pessoas, podendo ainda acentuar o processo de fragmentação das colônias, levando, em médio prazo, ao aumento do número de ninhos e, consequentemente, elevando a população ativa desses organismos (BUENO e CAMPOS-FARINHA, 1998). As bactérias encontradas neste experimento são comumente relacionadas com as infecções hospitalares. O controle de pragas desse hospital é feito rotineiramente conforme laudos de uma empresa especializada. Provavelmente, o número de formigas poderia ser maior, se não houvesse esse controle, ou a presença dessas formigas poderia estar ligada à ineficiência do produto utilizado.

Métodos preventivos, como conhecimento de colonização e forrageio das formigas, são importantes para o controle da disseminação de doenças em ambientes hospitalares (QUIRINO, 1997).

Antes de determinar as estratégias de controle, é fundamental conhecer a situação 
real da infestação de formigas por meio de monitoramento. Dados sobre biologia, ecologia e distribuição espacial contribuem para o manejo de formigas pragas, norteando as ações de controle e, dessa forma, reduzem os custos e riscos de contaminação ambiental (ZARZUELA, RIBEIRO e CAMPOSFARINHA, 2002).

A existência de formigas em locais considerados críticos, como hospitais, juntamente com as elevadas taxas de bactérias patogênicas associadas, pode representar riscos potenciais nas transmissões bacterianas que ocasionam infecções hospitalares.

\section{Conclusão}

Portanto, a relevância das descobertas enquadra-se em entender, de forma definitiva, o papel dos artrópodes como potenciais vetores de micro-organismos oportunistas nos hospitais, sendo fonte de infecções para pacientes imunodeprimidos.

\section{Agradecimentos}

À UNIFAL/MG pela oportunidade de desenvolver pesquisa científica e ao PIBIC/CNPQ pelo apoio financeiro.

\section{Referências}

1. BEATSON, S.H. Pharaoh's ants as pathogens vectors in hospitals. The lancet. 1972; v.1, n.19, p.425-427.

\section{BUENO, O.C. \& CAMPOS-FARINHA,}

A.E.C. Formigas urbanas: comportamento das espécies que invadem as cidades brasileiras. Revista Vetores e Pragas. 1998; v.1, n.12, p.13-6.

3. CARNEIRO, L.C.; CARVALHARES, T.T.; PESQUERO, M.A.; QUINTANA, R.C.; FEITOSA, S.B.; FILHO, J.L.; et al. Identificação de bactérias causadoras de infecção hospitalar e avaliação da tolerância a antibióticos. NewsLab. 2008; v.86, p.106-14.

4. DIENSTMANN, R.; PICOLI, S.U.; MEYER, G.; SCHENKEL, T.; STEYER, J. Avaliação fenotípica da enzima Klebsiella pneumoniae carbapenemase (KPC) em Enterobacteriaceae de ambiente hospitalar. J Bras Patol Med Lab. 2010; v.46, n.1, p.23-7.

5. FONTANA, R.; WETLER, R.M.C.; AQUINO, R.S.S.; ANDRIOLI, J.L.; QUEIROZ, G.R.G.; FERREIRA, S.L.; et al. Disseminação de bactérias patogênicas por formigas (Hymenoptera Formicidae) em dois hospitais do nordeste do Brasil. Neotropical Entomology. 2010; v.39, n.4, p.655-63.

6. FREITAS, M.R. \& TEIXEIRA, I.R.V. A formiga fantasma (Tapinoma melanocephalum) domina os ambientes hospitalares em Guaxupé, MG. In: Anais do VIII Congresso de Ecologia do Brasil, Caxambu-MG; 2007. 
7. MENEZES, E.A.; CARNEIRO, H.M.;

CUNHA, F.A.; OLIVEIRA, I.R.N.;

ÂNGELO, M.R.F.; SALVIANO, M.N.S.

Freqüência de microrganismos causadores de infecções urinárias hospitalares em pacientes do hospital geral de Fortaleza. RBAC. 2005; v.37, n.4, p.243-246.

8. PELLI, A.; TEIXEIRA, M.M.; COSTA, S.B.; CARVALHO, G.P.; OLIVEIRA, A.G.; TERRA, A.S.; et al. Formigas como vetores mecânicos de microorganismos no Hospital Escola da Universidade Federal do Triângulo Mineiro. Rev Soc Bras Med Trop. 2006; v.39, p.527-529.

\section{PEREIRA, R.S. \& UENO, M. Formigas} como veiculadoras de microrganismos em ambiente hospitalar. Rev Soc Bras Med Trop. 2008; v.41, n.5, p. 492-495.

10. QUIRINO, N.E.P.S. Infecção hospitalar: Epidemiologia e controle. Controle da água e vetores. São Paulo: Medsi. 1997; 219-228.

\section{RITCHMANN R. Guia Prático de}

Controle de Infecção Hospitalar. Soriak Comércio e Promoções S.A, Eurofarma Laboratórios Ltda, São Paulo. 2005.

\section{SANTOS, P.F.; FONSECA, A.R.;}

SANCHES, N.M. Formigas (Hymenoptera: Formicidae) como vetores de bactérias em dois hospitais do município de Divinópolis, Estado de Minas Gerais. Rev Soc Bras Med Trop. 2009; v.42, n.5, p.565-569.

\section{SCHULLER, L. Microorganismos} patogênicos veiculados por formigas andarilhas em unidades de alimentação. Revista de Saúde Pública. 2004; s.n, 75p. ilus, tab.

\section{SOCOLOWSKY, P.; CINTRA, P.}

Histórico sobre as pesquisas com formigas em ambientes hospitalares no Brasil.

Universidade Estadual Paulista; Hospital das Clínicas de Botucatu (SP). In: XVIII Simpósio de Mirmecologia. Botucatu, Universidade Estadual Paulista, Hospital das Clínicas de Botucatu; 2007.

15. TANAKA, I.I.; VIGGIANI, A.M.F.S.; PERSON, O.C. Bactérias veiculadas por formigas em ambiente hospitalar. Faculdade de Medicina de Marilia (FAMEMA). Arq Med ABC. 2007; v.32, n.2, p.60-63.

16. WETLER, R.M.C.; CARVALHO, E.S.; CHAVES, N.A.; DELABIE, H.C.; FONTANA, R. Formigas como vetor de propagação bacteriana: uma comparação entre formigas coletadas do campus da UESC e de um hospital público de Ilhéus (BA). In: Anais do $11^{\circ}$ Seminário de Iniciação Científica da UESC e $8^{\text {a }}$ Semana de Pesquisa e Pósgraduação (Ciências Biológicas); 2004. 
18. ZARZUELA, M.F.M.; RIBEIRO,

17. ZARA, F.J.; CAETANO, F.H.; JAFFÉ, K.

Formigas: biologia e anatomia. Rio Claro

(SP): Editora Topázio; 2002. 131p.

\section{M.C.C.; CAMPOS-FARINHA, A.E.C.}

Distribuição de formigas urbanas em hospital da região sudeste do Brasil. Arquivos do Instituto Biológico. 2002; v.69, p.85-87. 